\title{
A INCIDÊNCIA DO PROCESSO DE DESINDUSTRIALIZAÇÃO NOS ESTADOS BRASILEIROS
}

\author{
Marisa dos Reis A. Botelho* \\ Graciele de Fátima Sousa * \\ Ana Paula M. de Avellar*
}

\section{Resumo}

Os processos de desindustrialização têm sido objeto de intenso debate acadêmico nos últimos anos. Parte-se do ponto de vista de que há sinais inequívocos de um processo de desindustrialização na economia brasileira. Entretanto, em função do tamanho do país e de suas significativas desigualdades regionais, o processo de desindustrialização não se apresenta de modo uniforme em todas as regiões brasileiras. O objetivo central do artigo é apresentar as evidências do processo de desindustrialização por meio da ótica regional, apresentando dados recentes da produção e inserção externa. Por meio de indicadores de evolução do PIB industrial, emprego, produtividade, densidade industrial e inserção externa pode-se concluir que a incidência do processo de desindustrialização nos estados e regiões brasileiras não foi suficiente para alterar, de forma significativa, a forte concentração da indústria no Sul-Sudeste do país.

Palavras-chave: Desindustrialização; Desigualdades regionais; Brasil.

\begin{abstract}
The deindustrialization has been the subject of intense academic debate in recent years. We take for grant that there are clear signs of an ongoing process of deindustrialization in the Brazilian economy. However, considering the size of the country and its regional distinct levels of development, the process of deindustrialization does not present itself uniformly among the distinct regions. The main purpose of this study is to evaluate the regional heterogeneity of the ongoing process of deindustrialization with the help of a set of indicators of the Brazilian states. We use the indicators of the manufacturing industry share in the GDP, employment, industrial density, labor productivity and the balance of trade in manufacturing goods. The aforementioned distinct indicators allow us to conclude that the Brazilian process of deindustrialization encompasses, unequivocally, all states, albeit its intensity is not uniform, and the incidence in the states was not sufficient to significantly change the strong concentration of industry in the South-Southeast.
\end{abstract}

Key words: Deindustrialization; Regional inequalities; Brazil.

\section{Códigos J EL: L6; R0}

\footnotetext{
* Universidade Federal de Uberlândia

- Universidade Estadual de Campinas
} 


\section{Introdução}

Os processos de desindustrialização têm sido objeto de intenso debate acadêmico nos últimos anos. Para países em desenvolvimento, este debate tem apresentado posições divergentes quanto à sua ocorrência, intensidade e precocidade. Este último aspecto tem sido mais fortemente debatido em função de evidências que sugerem a ocorrência de "maldição dos recursos naturais", ou "doença holandesa", em alguns países.

Dentre os países em desenvolvimento, o Brasil figura entre aqueles que apresentam uma estrutura industrial diversificada e complexa, tendo sido a indústria o setor dinâmico da economia até o início da década de 1980. Após este período, a indústria brasileira começa a enfrentar dificuldades que permanecem até os dias atuais e que se refletem em perda de dinamismo e capacidade de liderar o crescimento econômico.

Os estudos recentes sobre o fenômeno da desindustrialização brasileira também apresentam posições divergentes sobre a sua ocorrência e intensidade, verificando-se que, em grande medida, as posições baseiam-se em diferentes marcos teórico-conceituais.

Este trabalho parte do ponto de vista de que há sinais inequívocos de um processo de desindustrialização em curso na economia brasileira. Há indicadores consistentes que apontam para um processo de perda de importância da indústria para o crescimento econômico (OREIRO; FEIJÓ, 2010; SAMPAIO, 2012; SARTI; HIRATUKA, 2010; NASSIF et al., 2015) e para a ocorrência de "doença holandesa" (PALMA, 2005; VERÍSSIMO, 2010).

Entretanto, em função do tamanho do país e de suas significativas desigualdades regionais, o processo de desindustrialização não se apresenta de modo uniforme em todas as regiões e estados brasileiros. O processo de liberalização econômica levado à cabo desde o início da década de 1990, com a consequente ausência de uma política industrial norteadora das ações de desenvolvimento industrial, somada às estratégias de atração de investimentos empreendidas, sobretudo pelos estados mais atrasados (a denominada "guerra fiscal”), determinaram alterações no mapa da indústria do país.

O presente trabalho pretende contribuir para o debate sobre o processo de desindustrialização no Brasil ao analisar como este processo se apresenta em nível regional, tomando como unidade de análise os estados brasileiros. $\mathrm{O}$ objetivo central da investigação é o de verificar se o processo de desindustrialização em curso tem provocado mudanças na localização industrial do país, de modo a corroborar ou não as históricas desigualdades regionais brasileiras. Para cumprir este objetivo são apresentadas as evidências do processo de desindustrialização na economia brasileira sob a ótica estadual, por meio de dados recentes da produção e inserção externa da indústria dos 26 estados brasileiros e do Distrito Federal.

Além dessa introdução e das considerações finais, o artigo contém duas seções. Na seção 2 apresenta-se a tese da desindustrialização na literatura econômica, onde são expostos os principais conceitos, além de conter também uma revisão da literatura que discute as evidências do processo de desindustrialização para a economia brasileira. A seção 3, que contém o núcleo principal do artigo, 
apresenta as evidências de desindustrialização no Brasil desagregando os indicadores para os estados brasileiros. Por meio de indicadores de PIB industrial, emprego, produtividade, densidade industrial e inserção externa mostra-se como o processo de desindustrialização apresenta-se nos estados e quais seus efeitos em termos de mudanças nas desigualdades regionais.

\section{A Tese de Desindustrialização na Literatura Econômica e Evidências para o Brasil}

Diversos autores na literatura econômica apontam para a importância da estrutura e do desenvolvimento industrial no desempenho da economia. Para Hirschman (1958), o dinamismo do setor industrial influencia o desempenho da economia por meio de efeitos de encadeamento, externalidades positivas e efeitos de transbordamentos para os demais setores. O setor industrial apresenta um elevado nível de encadeamento para frente e para trás, quando se compara com os demais setores da economia, de tal modo que a sua capacidade de dinamizar a economia foi destacada por Kaldor (1957, 1989), além de outros autores. O referido autor desenvolve um conjunto de pressupostos que enfatizam o papel do crescimento da atividade manufatureira para o crescimento econômico (primeira lei) e a relação entre o produto e a produtividade do trabalho na manufatura derivada dos retornos crescentes de escala dinâmicos e estáticos (segunda lei, também conhecida como lei de Kaldor-Verdoorn).

Deste modo, pode-se afirmar que a indústria é fundamental para o dinamismo da economia, sendo a fonte geradora de "retornos crescentes de escala e a fonte difusora do progresso técnico e permite o relaxamento da restrição externa ao crescimento de longo prazo" (OREIRO; FEIJ Ó, 2010: 224).

Assim, um processo de desindustrialização é prejudicial para o dinamismo da economia. Porém, qual o conceito por trás do termo desindustrialização?

Rowthorn e Ramaswany (1999) consideram que desindustrialização é a diminuição da participação relativa do emprego industrial no emprego total de uma economia. Tal definição é completada com o trabalho de Tregenna (2009) que apresenta uma redefinição do termo, considerando que desindustrialização é a redução da participação do emprego industrial no total de emprego de uma economia, juntamente com a diminuição do valor adicionado no Produto Interno Bruto (PIB). Ou seja, trata-se de uma diminuição relativa da indústria e não de uma redução absoluta.

Oreiro (2009: 1), que compartilha da visão de Rowthorn e Ramaswany (1999) e Tregenna (2009), considera que a desindustrialização ocorre, "quando o setor industrial perde importância como fonte geradora de empregos e/ ou de valor adicionado para uma determinada economia".

O processo de desindustrialização apresenta peculiaridades, caracterizando-se como uma desindustrialização natural/positiva ou precoce/negativa.

A desindustrialização natural, abordada no trabalho de Rowthorn e Ramaswamy (1999), é um processo natural do desenvolvimento econômico, estando associada com o alto nível de renda per capita. Sampaio (2012) mostra 
que a desindustrialização que aconteceu nos países desenvolvidos está ligada ao progresso técnico do setor industrial e o aumento da produtividade da indústria foi superior ao crescimento da produtividade do setor de serviços. Estes elementos somam-se ao aumento do percentual de participação de produtos de maior conteúdo tecnológico e maior valor agregado nas exportações, caracterizando assim a desindustrialização positiva.

A desindustrialização precoce se processa em um momento em que a economia de uma região apresenta um baixo dinamismo (baixo nível de renda per capita) com um setor industrial imaturo, alterações decorrentes de seu modo de inserção na globalização produtiva, com déficits comerciais crescentes na indústria e superávits crescentes no setor não-industrial. (ROWTHORN; RAMASWAMY, 1999). Observa-se a desindustrialização negativa sendo acompanhada de uma redução do peso de participação dos produtos de maior conteúdo tecnológico nas exportações.

Palma (2005), ao discutir a temática desindustrialização e doença-holandesa, aponta quatro fontes para a desindustrialização e apresenta uma nova estrutura teórica sobre a "desindustrialização prematura" presente nas economias latinoamericanas, incluindo o Brasil. Os fatores apontados pelo autor como explicação para a desindustrialização são: i) um "U" invertido da relação entre emprego da manufatura e renda per capita, determinado por diminuição do emprego industrial e realocação para os serviços, como um resultado natural do processo de desindustrialização; ii) uma relação em "U" invertido entre renda per capita e emprego industrial em países de média e alta renda, determinado por realocação de parte das atividades industriais no setor de serviços ("ilusão estatística"), redução da elasticidade-renda de produtos industriais, alta produtividade da indústria manufatureira ou realocação de atividades manufatureiras para países em desenvolvimento; iii) um declínio na renda per capita que corresponde ao ponto de virada da regressão, indicando que o processo de desindustrialização passa a atingir países de renda média; iv) a doença holandesa. Para o autor, este último fator seria o determinante dos processos de desindustrialização por que passa o Brasil e outros países latino-americanos, em virtude das políticas de abertura comercial e financeira implementadas nos anos 1990.

Portanto, as causas principais do processo de desindustrialização elencadas pelos autores são: i) o próprio desenvolvimento econômico, no qual haveria uma tendência natural de desindustrialização nas economias, mediante aumento do padrão de vida, relacionado com mudanças na relação da elasticidade renda da demanda por produtos industrializados e serviços; ii) questões ligadas ao aumento de produtividade na indústria superior ao do setor de serviços; iii) fatores externos, como uma abertura comercial implicando em especialização produtiva nos países.

Dentre os autores que analisaram o processo de desindustrialização no Brasil destacam-se Oreiro e Feijó (2010), que mostram que o primeiro trabalho a apontar para a desindustrialização brasileira foi o de Marquetti (2002). Marquetti (2002 apud OREIRO; FEIJÓ, 2010), ao investigar a participação industrial no PIB do país e analisar os dados da indústria de transformação, mostrou que o Brasil passou por uma desindustrialização negativa nos anos de 1980 e 1990, devido ao baixo investimento realizado no setor industrial neste 
período, verificando-se uma redução da participação do emprego e do valor adicionado industrial na economia.

Como apresentado nos trabalhos de Bonelli (2008), Nassif (2008), Squeff (2009), Oreiro e Feijó (2010), a indústria vinha apresentando aumento de participação na produção nacional ao longo das décadas de 1950 a 1980. Porém, a partir de meados dos anos de 1980 houve uma redução significativa da participação da indústria no PIB brasileiro, uma queda de $42 \%$ (1985) para 31\% (1995) (SQUEFF, 2009) e uma diminuição relativa da indústria de transformação na produção nacional de 31\% em 1985 para apenas 20\% em 1995 (BONELLI, 2008). Com base nos argumentos apresentados nesses trabalhos, está havendo um processo de desindustrialização na economia brasileira, caracterizada pela perda de participação relativa da indústria no PIB.

Soares et al. (2011), com base em informações de 1996 a 2008 e aplicando os modelos de Rowthorn e Ramaswamy (1999) para Brasil, consideram que não há uma desindustrialização absoluta no Brasil, visto que o produto e o emprego industrial aumentaram no período analisado. Contudo os autores apontam que há uma perda relativa, mesmo que irregular, no produto e empregos industriais nos últimos anos.

Nassif (2008) apresenta inicialmente posição divergente. O autor analisa a perda de importância da indústria em termos de participação no PIB na segunda metade dos anos 1980, com forte retração da produtividade do trabalho, mas não classificou esse processo como desindustrialização em virtude de ter precedido as reformas econômicas do início dos anos 1990 e estar relacionado à situação macroeconômica (estagnação e inflação). Nos anos 1990, houve manutenção da participação da indústria no PIB (22\%), com aumento da produtividade do trabalho e queda na taxa de investimento.

Entretanto, em trabalhos posteriores, Nassif et al. (2015) e Bresser-Pereira et al. (2016), este autor reviu essa posição. Em Nassif et al. (2015), mostra-se que o país vem sofrendo um processo de desindustrialização precoce desde os anos 1990 e assumindo uma trajetória de falling behind em relação à economia mundial.

Em uma posição intermediária, estão autores que avaliam como preocupante a evolução recente da indústria brasileira, mas não diagnosticam a ocorrência de um processo de desindustrialização definitivo. Sarti e Hiratuka (2010) entendem que, diferentemente de outras experiências, a base industrial brasileira manteve uma maior complexidade, densidade e capacidade de encadeamentos produtivos e tecnológicos. Para os autores, foi essa situação que permitiu a configuração de um novo padrão de crescimento a partir de 20042005 e de um breve ciclo de investimento no período 2006-2008, que antecedeu a grave crise internacional ${ }^{1}$.

Para Kupfer (2012), há perdas de competitividade da indústria brasileira, dado o círculo vicioso marcado por especialização regressiva (concentração em indústria de recursos naturais desde a década de 1990) e pela perda de

1 A possibilidade de estancar o processo de desindustrialização em virtude do tamanho e diversificação da indústria brasileira também é analisado em Nassif et al. (2015) e BresserPereira et al. (2016). 
densidade das cadeias produtivas, lenta evolução da produtividade e aumento do hiato tecnológico².

Trabalhos que analisam o processo de desindustrialização tomando como referência a sua ocorrência nos subespaços nacionais são mais escassos na literatura de referência. Cruz e Santos (2011) realizam análise semelhante à proposta no presente trabalho, mas centram-se na evolução do emprego industrial tomando como referência as microrregiões brasileiras. A partir da análise de microrregiões ganhadoras e perdedoras, o estudo conclui que a maior parte das ganhadoras se situa na direção Noroeste, da região Centro-Oeste aos estados do Sul, em especial Paraná e Santa Catarina. Entretanto, os dados indicam que apesar da perda de empregos industriais no Sudeste, as indústrias de maior conteúdo tecnológico tenderam a se concentrar nesta região.

As conclusões deste trabalho confirmam a tese do desenvolvimento poligonal, desenvolvida por Diniz (1993). Segundo este autor, houve um processo de desconcentração regional da produção industrial brasileira entre o os anos 1960 e o início dos anos 1990, que se restringiu ao Centro-Sul do país. Este processo situou as regiões mais industrializadas do Brasil em um polígono, definido pelos municípios de Belo Horizonte - Uberlândia - Londrina/Maringá - Porto Alegre Florianópolis - São J osé dos Campos - Belo Horizonte.

A partir de metodologia distinta, Lemos et al. (2003: 692) chegam à conclusão semelhante. A partir da utilização do modelo gravitacional, demonstram que "o padrão do desenvolvimento regional brasileiro não parece ter experimentado mudança estrutural entre 1980 e 1991, uma vez que os grandes contornos geográficos da economia brasileira continuam semelhantes. "3

\section{Evidências da desindustrialização no Brasil: uma análise em nível estadual}

A metodologia utilizada neste estudo foi desenvolvida no contexto de uma investigação acerca do debate do processo de desindustrialização, com ênfase na economia brasileira, sendo que será realizada uma verificação desse processo para os 26 estados brasileiros e o Distrito Federal. O presente estudo pretende investigar a desindustrialização relativa e absoluta, assim como variáveis de exportação e importação industrial.

\footnotetext{
2 Deve-se destacar que há trabalhos que analisam o processo de desindustrialização no Brasil sob uma ótica "positiva". É o caso dos trabalhos de Bonelli e Pessoa (2010) e Bonelli et al. (2013). Para esses autores, o país estava "sobreindustrializado", pois apresentava uma participação da indústria no PIB superior à média mundial nas décadas de 1970 e 1980. Como estes trabalhos partem de enfoques teóricos distintos, não serão objeto de análise neste artigo. 3 A regionalização da produção industrial brasileira sofre importantes efeitos da "guerra fiscal" entre os estados iniciada com as mudanças estruturais do início dos anos 1990. Há um conjunto significativo de trabalhos que se propõem a analisar este tema. Pode-se citar, a título de exemplo, o trabalho de Cardozo (2010). A discussão desse tema foge ao escopo deste trabalho.
} 
Considerando desindustrialização a perda de importância relativa da indústria ${ }^{4}$ na economia, este estudo irá investigar este processo utilizando, para todos os estados, estatísticas descritivas de dados secundários referentes à:

- $\quad$ Participação do PIB industrial no PIB. Esses dados são elaborados pelo Instituto Brasileiro de Geografia e Estatística (IBGE) e coletados no site oficial do Instituto de Pesquisa Econômica Aplicada (IPEA) e deflacionados segundo o Índice de Preços ao Consumidor (IPC) da Fundação Getúlio Vargas (FGV), tendo o último ano da série como referência (2013).

- $\quad$ Densidade produtiva, que é relação do Valor da Transformação Industrial (VTI) pelo Valor Bruto da Produção Industrial (VBPI). Os valores absolutos de VTI e VBPI foram obtidos na base de dados da Pesquisa Industrial Anual (PIA) disponibilizada no site oficial do IBGE. Por serem variáveis monetárias, o VBPI e o VTI foram deflacionados segundo o Índice de Preços por Atacado (IPA) da FGV, tendo o último ano da série como referência (2012).

- $\quad$ Participação do emprego formal industrial no total do emprego formal, a partir da base de dados da Relação Anual de Informações Sociais (RAIS).

- $\quad$ Produtividade do trabalho, que é a relação do VTI pelo pessoal ocupado (PO). Esses dados foram obtidos na PIA/IBGE.

- Comércio exterior (participação da exportação industrial e importação industrial na exportação total e importação total, respectivamente extraído da Secretaria de Comércio Exterior (SECEX) do Ministério do Desenvolvimento, Indústria e Comércio Exterior (MDIC). Os valores de comércio exterior também foram deflacionados com base no IPC da FGV, tendo o último ano da série como referência (2013).

Ressalta-se que os dados estão desagregados por atividades industriais (seguindo a CNAE 2.0) e foram agrupados por intensidade tecnológica, conforme a classificação da Organization for Economic Cooperation and Development (OECD, 2005). O período analisado será de 1990 a 2013; porém, para os valores do PIB os dados são para o período de 1996 a 2013 e os dados de VTI, VBPI, produtividade e densidade produtiva referem-se ao período 19962012, em virtude de mudanças metodológicas na série da PIA 5 .

\footnotetext{
4 Neste artigo, o termo indústria refere-se ao somatório da indústria de transformação e indústria extrativa. Como a indústria extrativa é muito importante em alguns estados brasileiros, optou-se por considerar o total da indústria de modo a captar o movimento geral, e não só o da indústria de transformação. Ao longo do período analisado, a indústria extrativa aumenta a participação relativa no total da indústria até o ano de 2008, quando atinge 16,3\% do total, e perde participação nos anos seguintes, em virtude dos efeitos da crise internacional.

${ }^{5}$ Os dados que compõem este trabalho foram elaborados para todos os anos do período 199o2013. Por questões de espaço, apresentam-se apenas os dados do primeiro e último anos da série histórica. Em relação aos dados do PIB industrial, optou-se por utilizar como referência para a análise o período 1996-2013, dada a mudança metodológica ocorrida no ano de 1995, de modo a trabalhar apenas com a nova série. Apesar dessa mudança, não houve alteração de tendência nos dados, antes e depois da mudança, como pode ser aferido em FIESP (2015).
} 


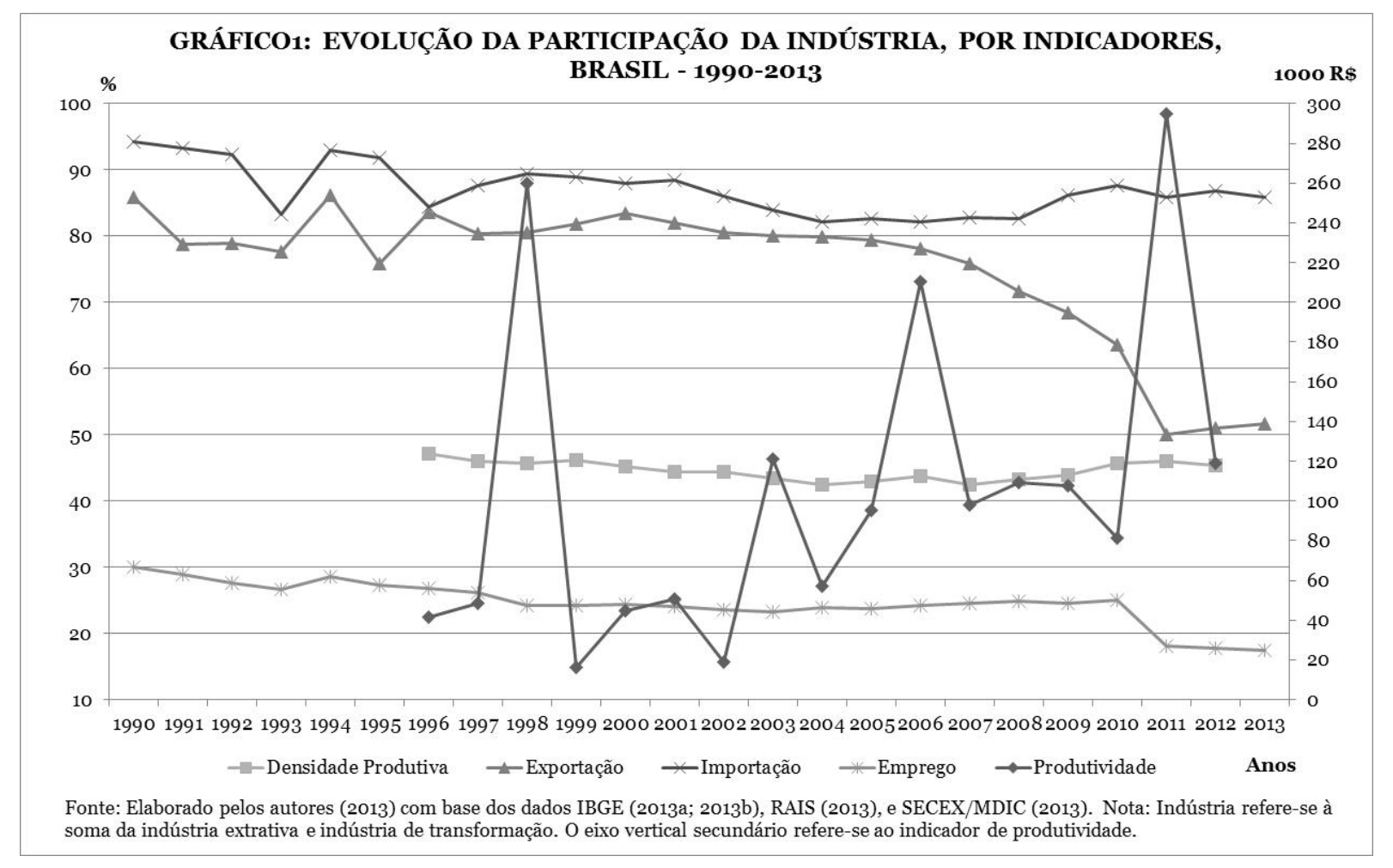

Em linhas gerais, para a indústria brasileira (gráfico1) pode-se observar que o indicador de densidade produtiva se manteve praticamente estagnado, durante o período 1996-2012, enquanto os indicadores de emprego, importação e exportação apresentaram trajetória decrescente em relação ao ano inicial destas séries, em 1990. Sendo que para o emprego e exportação, houve uma diminuição significativa no ano de 2010 para 2011.

Nas subseções seguintes, são apresentados os indicadores para cada estado brasileiro, para o primeiro e último ano da série. Os mesmos dados para o conjunto da economia brasileira estão no gráfico1, que contém os indicadores de todos anos da série e serão utilizados para fins de comparação e análise.

\subsection{Evolução do PIB Industrial}

A participação relativa da indústria na produção brasileira nas décadas de 19962000 sofreu uma redução em comparação com os valores verificados nos anos de 1980, apresentando uma queda de seis pontos percentuais no PIB (gráfico2). Esta queda é considerada por Oreiro e Feijó (2010) como evidência de um processo de desindustrialização na economia brasileira.

A análise da evolução do PIB industrial nos estados brasileiros (gráfico2) mostra que 23 estados também apresentaram uma diminuição relativa da sua indústria no PIB estadual, sendo que 5 dos 23 estados tiveram uma queda acima de dez pontos percentuais. Destaque para os estados de São Paulo, que apresentou

Segundo esse documento, o valor do PIB da indústria de transformação na série nova é, em média, 4,7\% menor do que na série antiga. 
uma perda relativa de 14 pontos percentuais (p.p.), Amazonas, com uma redução de 18p.p., e Santa Catarina com uma perda de 14p.p. cada.

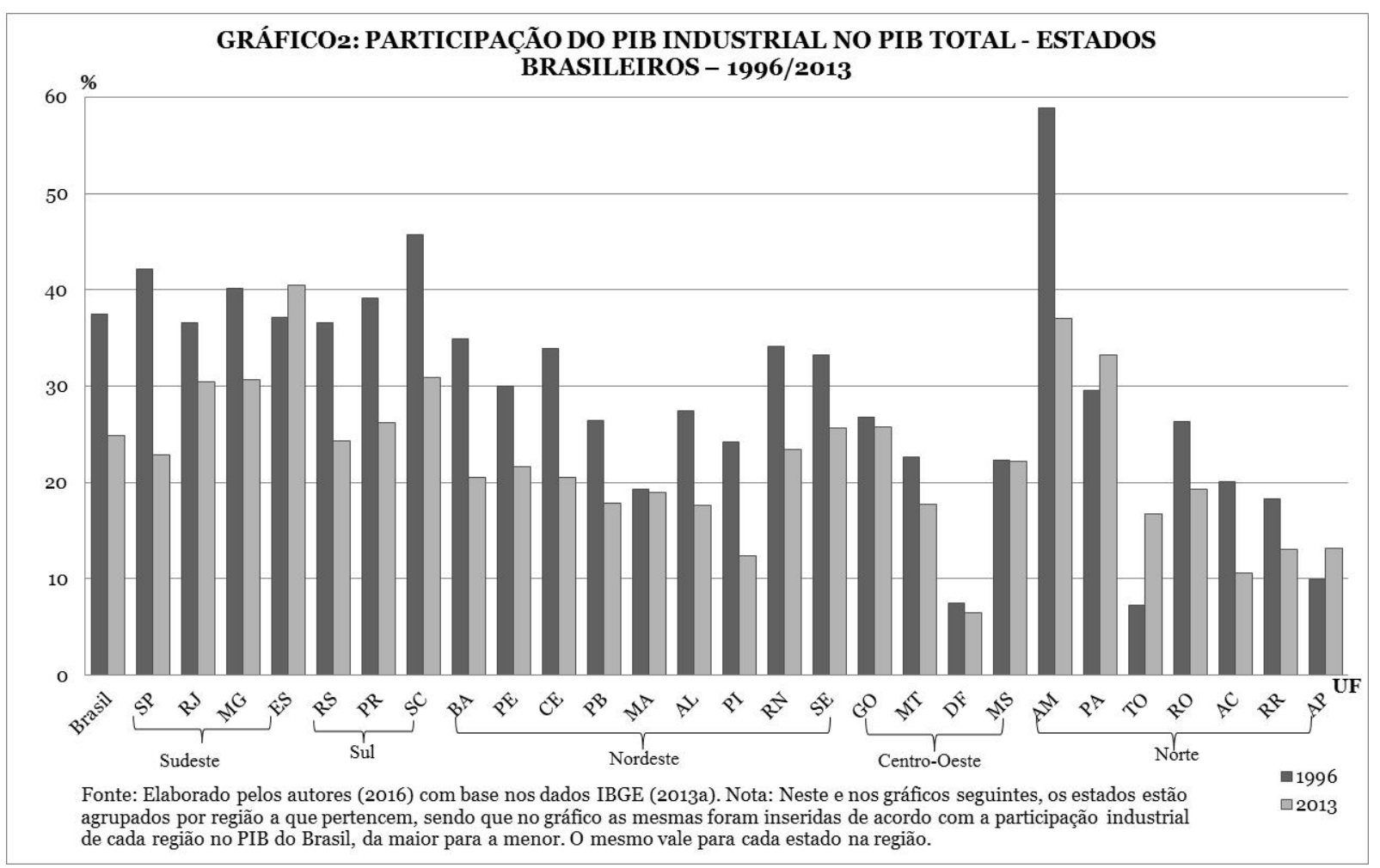

O Sudeste, que apresenta a maior participação industrial no PIB do Brasil e concentra os estados com as indústrias mais desenvolvidas tecnologicamente, também é a região em que se localiza o estado que apresentou uma das maiores quedas nos valores relativos da indústria, o estado de São Paulo. A maior economia estadual do país vivenciou um processo de desindustrialização relativa, sendo que o estado não apresentou indícios de recuperação.

Minas Gerais e Rio de Janeiro, juntamente com São Paulo, apresentaram redução nos percentuais de participação da indústria no PIB, caracterizando um processo de desindustrialização relativa. Houve uma ligeira tendência de recuperação da indústria do Espírito Santo a partir do ano de 2007, quando a economia brasileira apresenta forte expansão no PIB.

No Sul observou-se também um processo de desindustrialização relativa na indústria do Paraná e do Rio Grande do Sul, mas houve uma recuperação dos valores, a partir do ano de 2003, que não se manteve a partir de 2010. Em Santa Catarina, observa-se um processo de desindustrialização relativa, dado o crescimento no período dos valores absolutos do PIB industrial.

Na Região Nordeste todos os estados apresentaram acréscimo nos valores absolutos da indústria, comparando o final dos anos 2000 com a década de 1990. Em termos relativos, verifica-se que todos os estados do Nordeste tiveram algum decréscimo de participação da indústria. O destaque cabe aos estados que apresentaram as maiores diminuições de participação da indústria no PIB, como Bahia, Ceará, Piauí e Rio Grande do Norte, e aos estados que 
apresentaram uma ligeira recuperação na participação industrial no PIB, a partir de 2007, como Paraíba, que tornou a regredir no ano de 2013, e Maranhão, que apresentou uma estabilidade nos valores relativos no período em questão.

O Centro-Oeste apresentou comportamento distinto, dado que todos os estados apresentaram aumento absoluto do PIB industrial no período de 1996-2013, e apenas Mato Grosso registrou, significativamente, um percentual industrial na produção total inferior no ano de 2013 em comparação ao ano de 1996. Esta região, portanto, apresentou estabilidade na participação no PIB industrial brasileiro ao longo do período analisado.

Na Região Norte, todos os estados tiveram um aumento dos valores absolutos do PIB industrial no período de 1996-2013. Já com respeito à participação da indústria no PIB, a análise mostra que os estados do Norte que tiveram alguma diminuição ao longo dos anos analisados foram Amazonas, Acre e Tocantins.

Para as regiões Sul, Centro-Oeste e Norte, embora os dados indiquem que o processo de desindustrialização não tenha sido generalizado nos seus estados, deve-se destacar que, especialmente o Centro-Oeste e o Norte têm pequena participação na produção industrial brasileira. De todo modo, os dados analisados indicam que houve, ao longo do período analisado, avanços no processo de desconcentração industrial brasileira.

Em suma, pode-se dizer que o processo de desindustrialização pelo qual vem passando a economia brasileira se apresentou também na grande maioria dos estados brasileiros e de forma mais significativa nas regiões Sudeste e Nordeste. Os dados de PIB industrial indicam um processo de desindustrialização absoluta e relativa na região Sudeste e relativa na região Nordeste ${ }^{6}$.

\subsection{Evolução do Emprego Industrial}

Avaliando os dados de emprego e de participações dos diversos setores no emprego total, percebe-se que a participação do emprego da indústria no total do emprego da economia do Brasil reduziu-se significativamente do ano de 1990 a 2013, com uma queda de 12,17 pontos percentuais (p.p.), semelhante à queda verificada no PIB industrial. Entretanto, a trajetória dos valores absolutos do emprego industrial difere da do PIB industrial, porquanto há um aumento de

\footnotetext{
6 Quando a referência de análise é a classificação segundo a intensidade tecnológica, Silva e Cário (2012:10) mostram que os maiores valores de VTI estão concentrados nas atividades das indústrias de média-baixa e de baixa intensidade tecnológica. Entretanto, para esses autores, a menor participação das atividades mais intensas em tecnologia no VTI não é indicador da ocorrência de um processo de desindustrialização no Brasil, dado que estas atividades apresentaram ganhos de participação no VTI da indústria de transformação e, nos últimos anos, a indústria de alta tecnologia expandiu-se acima dos demais grupos. Então, "rejeita-se a hipótese de que o país esteja concentrando sua produção industrial em setores de mais baixa intensidade tecnológica, de forma que, na verdade, a tendência é de movimento inverso [...]". A análise dos autores não elabora desagregação em nível estadual, como a empreendida neste trabalho. Nas seções seguintes utiliza-se também a classificação segundo a intensidade tecnológica, a fim de dar mais robustez à análise.
} 
cerca de $60 \%$ no período 1990-2010. Mas, no período 1990-2013, o aumento do emprego industrial foi de apenas $24 \%$.

Esta trajetória de aumento do número absoluto de empregos industriais ocorreu em quase todos os estados brasileiros, sendo que Rio de Janeiro, São Paulo, Pernambuco e Amapá tiveram uma redução no número de empregos da indústria, no período de 1990-2013. Ressalta-se que as taxas de crescimento foram bastante díspares, variando de -1,1\% (Rio de J aneiro) a 8\% (Tocantins), no período de 1990-2013.

Como pode ser visualizado no gráfico3, há uma diminuição dos valores relativos do emprego industrial para todos os estados do Sudeste. Assim, pode-se dizer que os dados de evolução do emprego corroboram os de PIB industrial, indicando que há um processo de desindustrialização relativa nesta região. Entretanto, observa-se uma estabilidade dos valores em meados dos anos 2000, tendo uma nova trajetória de declínio a partir de 2011 a 2013.

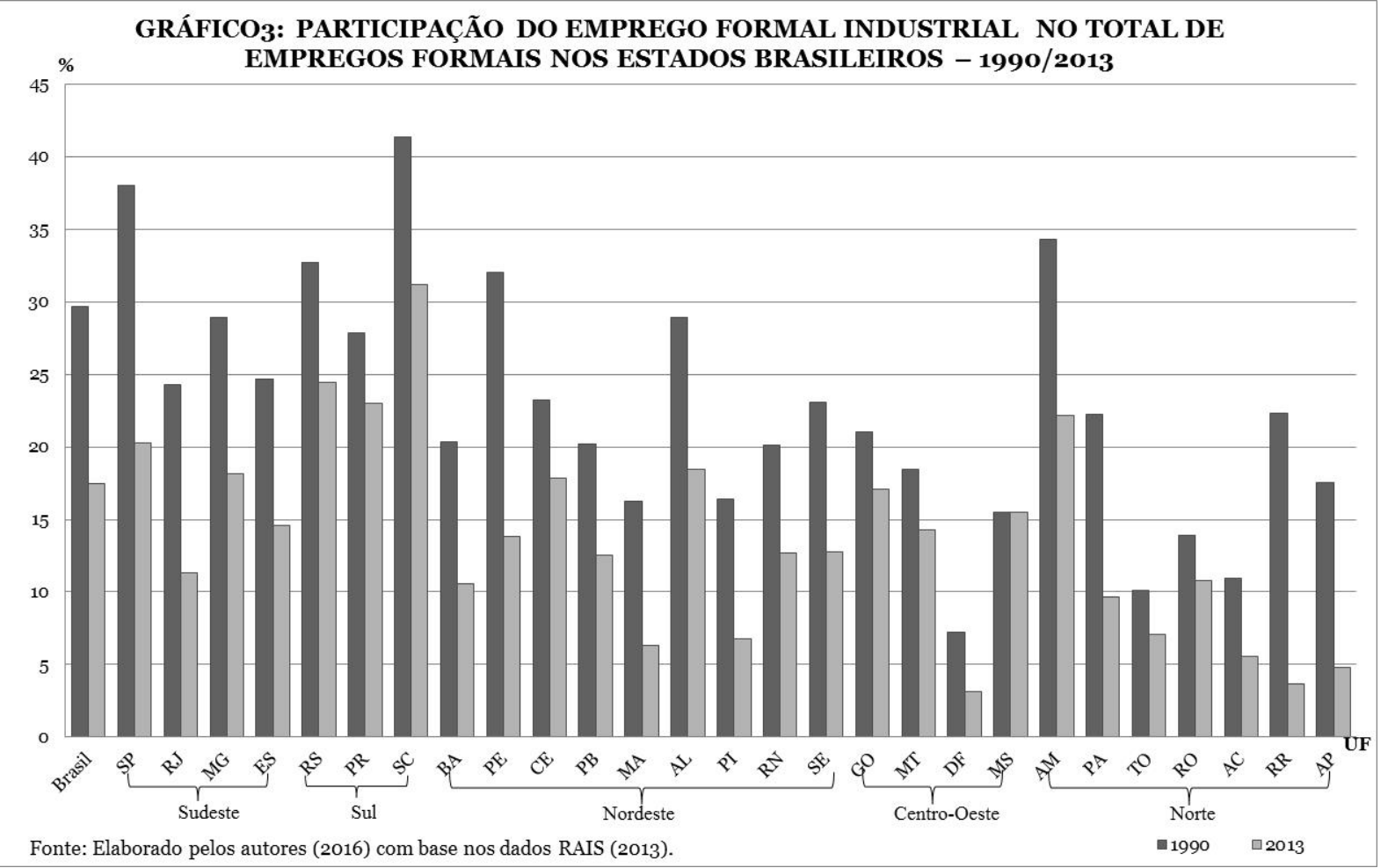

Na Região Sul, nenhum estado apresentou aumento da participação relativa do emprego industrial, sendo que a maior redução foi verificada em Santa Catarina (-10p.p.). Dentre os estados do Nordeste, também todos os estados tiveram redução nos valores relativos do emprego industrial. Pernambuco e Alagoas são os que vêm apresentando os maiores decréscimos da participação relativa do emprego industrial, uma queda de-18p.p. e-10p.p., respectivamente.

Situação semelhante foi verificada no Norte. Todos os estados apresentaram queda da participação relativa do emprego industrial, destaque para as reduções em Roraima (-18p.p.), Amapá (-12p.p.), Amazonas (-12p.p.), Pará (-12p.p.) e 
Acre (-5p.p.). No Centro-Oeste, os decréscimos mais significativos foram no Mato Grosso (-4p.p.) e Distrito Federal (-4p.p.), enquanto Mato Grosso do Sul apresentou estabilidade da participação relativa do emprego industrial.

Os dados de emprego industrial foram analisados segundo a classificação por intensidade tecnológica da OECD.

A análise detalhada da participação do emprego industrial por atividades industriais mostra que para o Brasil a maior perda foi verificada na indústria de baixa tecnologia (-2,8p.p.), sendo seguida pela de alta tecnologia (-1,07 p.p) e de média-baixa tecnologia (-0,22p.p.), enquanto a indústria de média-alta tecnologia apresentou um ganho de 0,27p.p.

Ao se desagregar estes dados por estados, observa-se que não houve muitas oscilações ao longo dos anos analisados, sendo que seis estados apresentaram uma trajetória estável da participação do emprego de cada grupo de indústria Piauí, Roraima, Acre, Distrito Federal, Roraima e Amapá.

Destaca-se que Paraíba e São Paulo, que foram os únicos estados que apresentaram, para todos os grupos de indústrias classificadas por intensidade tecnológica, uma queda de participação do emprego industrial. Em São Paulo, a indústria de baixa tecnologia teve as maiores reduções no emprego total, uma regressão de -3p.p., sendo seguida pelas atividades de alta tecnologia (-1,9p.p.).

Com relação à indústria de alta tecnologia, o maior decréscimo verificado no emprego ocorreu no Amazonas, que apresentou uma perda de 5p.p. do emprego desta indústria no emprego total do estado, especialmente devido à redução dos empregos gerados pela atividade Fabricação de material eletrônico. Santa Catarina, São Paulo, Rio Grande do Sul e Paraná também apresentaram diminuições do percentual de empregos da indústria de alta tecnologia no emprego total acima de um ponto percentual, enquanto outros quinze estados diminuíram a participação das atividades de alta tecnologia no emprego total, porém as reduções foram muito pequenas.

Em termos relativos, a diminuição dos empregos da indústria de média-alta tecnologia foi pequena e só ocorreu em Roraima, Rio de Janeiro, São Paulo, Pará, Paraíba, Ceará e Piauí. No Rio de Janeiro e no Pará a redução dos empregos da indústria de média-alta tecnologia sofreu o impacto do decréscimo de geração de empregos da atividade de Fabricação de produtos químicos.

Em sete estados verificou-se uma diminuição muito pequena do emprego da indústria de média-baixa tecnologia no emprego total, sendo que a única redução que ficou acima de um ponto percentual foi na Paraíba, e para os três estados a atividade Fabricação de Coque, de Produtos Derivados do Petróleo e de Biocombustíveis foi a principal responsável pelo desempenho declinante da participação dos empregos gerados na indústria de média-baixa tecnologia nos empregos totais desse estado.

Por fim, a redução do emprego da indústria de baixa tecnologia no emprego total aconteceu em 20 estados, no qual se destacam Amazonas, Santa Catarina, São Paulo, Rio Grande do Sul e Paraná que apresentaram um decréscimo acima de um ponto percentual. 
Em suma, os dados de evolução do emprego industrial, a despeito de algumas divergências em relação aos do PIB industrial, corroboram com a tese de que há um processo de desindustrialização em curso na economia brasileira. Apesar do aumento verificado no número de empregos absolutos no período 1990-2013, em quase todos os estados brasileiros (22 estados e o Distrito Federal) houve redução da participação do emprego industrial no emprego total. Os dados de emprego, segundo a classificação por intensidade tecnológica, mostram alterações muito pequenas no período analisado. Este é um sinal evidente de que a indústria de alta e média intensidade tecnológica segue concentrada no Sudeste do país, o que confirma os resultados encontrados por Cruz e Santos (2011) e reafirmam a tese de Diniz (1993).

Entretanto, como o decréscimo da participação do emprego industrial no emprego total pode resultar de aumentos de produtividade do setor, não significando necessariamente perda de dinamismo da indústria (NASSIF, 2008), analisa-se, na sequência, a evolução deste indicador.

\subsection{Evolução da Produtividade Industrial}

A produtividade relaciona-se com a competitividade industrial, já que aquela pode ser compreendida como a capacidade empresarial de promover um aumento na produção com economia de fatores produtivos, sendo que ganhos de produtividade refletem em ganhos de rentabilidade e aumento da capacidade de fazer investimentos. O aumento/diminuição de produtividade está relacionado a vários fatores internos ou externos à indústria. Ressalta-se que existem diversos cálculos para a produtividade, sendo que, neste trabalho, o indicador foi calculado pela razão entre o VTI e PO.

A análise neste artigo, assim como no trabalho de Nassif (2008), mostra um aumento significativo da produtividade do trabalho na indústria do Brasil na década de 1990 (1996-1999) ${ }^{7}$ e uma tendência ao declínio nos anos 2000. Em termos estaduais percebe-se que todos os estados tiveram uma trajetória de crescimento do valor do indicador de produtividade industrial, comparando o ano inicial (1996) com o ano final (2012) da análise deste trabalho (gráfico4).

No Sudeste, Rio de Janeiro e Espírito Santo têm elevação muito superior no período analisado; no caso do Rio de Janeiro, o seu crescimento foi inferior somente ao verificado para o Pará. Este estado, somado ao Amazonas e Amapá, são os que apresentaram elevação da produtividade no Norte do país.

\footnotetext{
${ }^{7}$ Vale ressaltar a existência de um importante debate no Brasil sobre as causas do crescimento da produtividade industrial nos anos 1990. Uma das perspectivas mais consolidadas na literatura considera que o aumento da produtividade industrial nesse período foi resultado de um processo de modernização/reestruturação produtiva da indústria, dado que as empresas, por exemplo, passaram a adotar estratégias de "terceirização" em várias atividades, não diretamente relacionadas ao processo produtivo. Como decorrência desse movimento evidenciase uma queda acentuada no número de pessoal ocupado na indústria que, por consequência estatística, ampliou o indicador de produtividade sem a ocorrência de um aumento significativo da eficiência da produção, ou seja, da produtividade. (FEIJ Ó e CARVALHO, 1993; CARVALHO E FEIJÓ, 2000).
} 
No Sul, os maiores crescimentos da produtividade foram verificados no Paraná e Rio Grande do Sul. Já no Centro-Oeste destaque para os acréscimos no Mato Grosso e Mato Grosso do Sul.

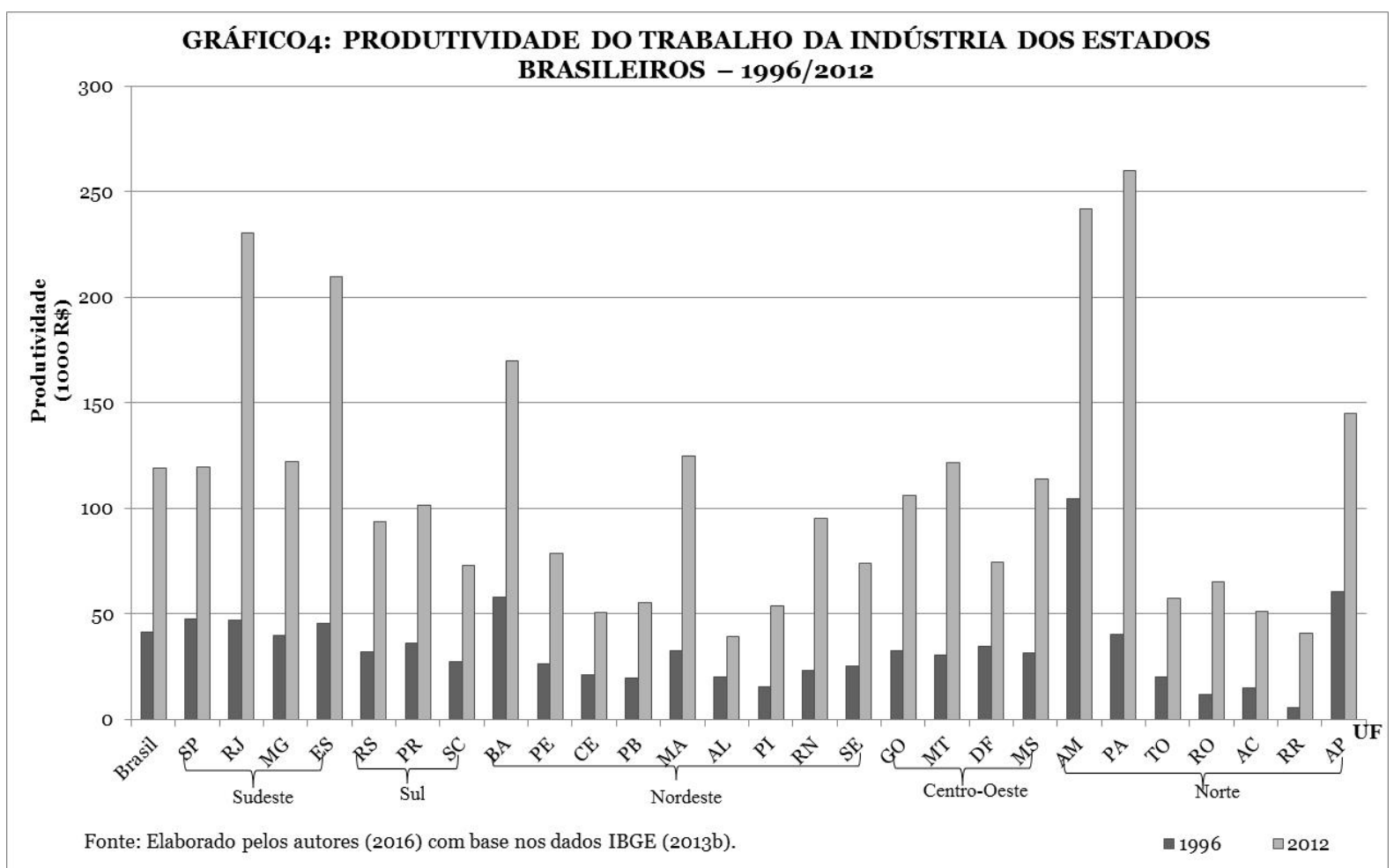

Considerando-se a classificação por intensidade tecnológica, a indústria de alta tecnologia apresentou o maior aumento no valor de produtividade, em comparação às demais indústrias. Quando se analisa os dados estaduais segundo esta classificação, não se identifica nenhum padrão. Há estados de todas as regiões que obtiveram ganhos mais expressivos de produtividade nas indústrias de alta, média e baixa intensidade tecnológica.

Ademais, os ganhos de eficiência da indústria de Rio de J aneiro, Espírito Santo e Minas Gerais) vão ao encontro dos resultados encontrados por Cruz e Santos (2011). Para estes autores, a diminuição do emprego industrial no Sudeste vem acompanhada de uma concentração de atividades de maior intensidade tecnológica nesta região, atividades estas mais propensas à ganhos de produtividade mais elevados.

\subsection{Evolução da Densidade Produtiva Industrial}

A densidade produtiva industrial, obtida pela razão entre o VTI e o VBPI, visa avaliar a evolução da capacidade das atividades industriais em agregar valor na produção nacional. A relação VTI/VBPI, de acordo com Almeida, Feijó e Carvalho (2007: 1), "quando decrescente, denota que há um maior uso de insumos importados representando, para o conjunto da indústria, transferência de produção e de seu respectivo valor agregado para o exterior". Quanto mais 
próximo de $100 \%$ é o valor da relação VTI/VBPI, mais a produção é intensiva em valor agregado gerado no próprio país.

Ao analisar os elos das cadeias industriais, com base na densidade produtiva, observa-se uma queda ao longo de 1996-2012, o que se soma aos indicadores anteriores para mostrar o processo de desindustrialização em curso na economia brasileira ${ }^{8}$. Entre os estados, verifica-se que em 15, dos 27 estados brasileiros, houve perda na relação VTI/VBPI. Em relação aos estados que obtiveram ganhos de densidade produtiva superiores à média nacional no período, os maiores aumentos foram verificados em Roraima, Espírito Santo, Pará, Mato Grosso do Sul, Paraíba, Rio de Janeiro o que não configura uma tendência regional específica (gráfico5).

Todos os grupos industriais brasileiros classificados por intensidade tecnológica regrediram em termos de capacidade relativa de agregar valor na comparação entre 1996 e 2012, sendo que as maiores perdas foram verificadas na indústria de alta tecnologia (-8,7p.p.) e na indústria de média-alta tecnologia (-7,6p.p.), que são os grupos de atividades considerados como principais geradores e difusores do progresso tecnológico.

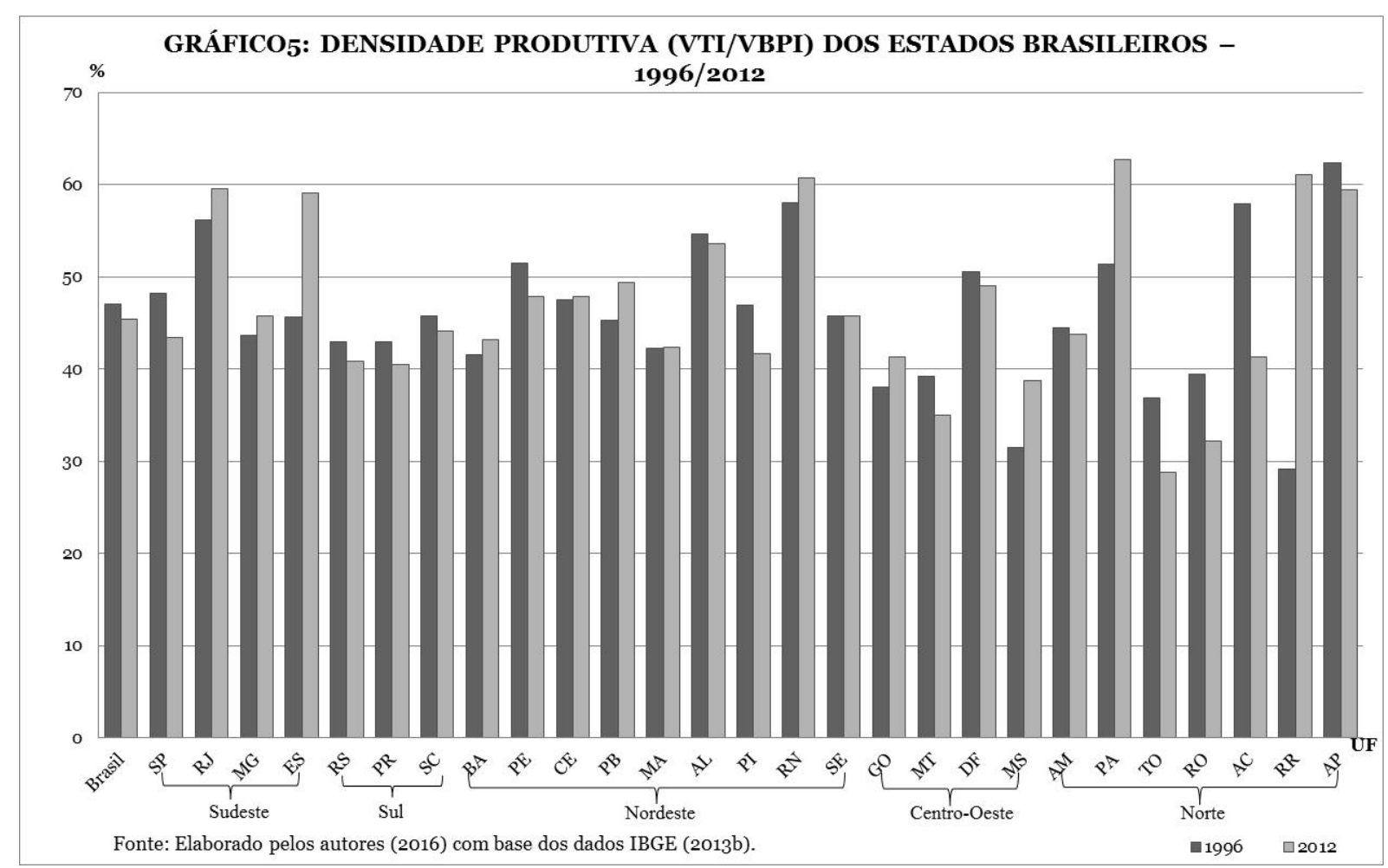

Analisando a relação VTI/VBPI a partir da classificação das atividades industriais por intensidade tecnológica, tem se que no grupo de alta tecnologia as maiores reduções do VTI/VBPI ocorreram no Maranhão (-58p.p.), Alagoas (52p.p.), Paraíba (-42p.p.) e Pernambuco (-29p.p.). Além disso, Sergipe (-

\footnotetext{
${ }^{8}$ Silva e Cário (2012) usam a mesma base de dados e o mesmo indicador de densidade industrial. Entretanto, diferentemente do presente artigo, os autores não desagregam a base de dados para os estados brasileiros.
} 
28p.p.), Bahia (-20p.p.), Pará (-17p.p.), Goiás (-14p.p.), Mato Grosso (-9p.p), São Paulo (-9p.p.), Espírito Santo (-8,8p.p.), Paraná (-8,4p.p.), Amazonas (7,6p.p.), Piauí (6,6p.p.), Minas Gerais (5,8p.p.), Ceará (-2,6p.p) e Rio de J aneiro (-2,5p.p) também apresentaram, em menor grau, enfraquecimentos nos seus elos produtivos na indústria de alta tecnologia.

Para o grupo de média-alta tecnologia, 20 estados apresentaram uma redução no VTI/VBPI, especialmente em Tocantins (-52p.p.), Goiás (-28p.p.), Rondônia (-25p.p.), Maranhão (-19p.p.), Piauí (-18p.p.), Ceará (-17p.p.) e Mato Grosso do Sul (-11p.p.).

No grupo de indústria de média-baixa tecnologia, a maior redução ocorreu no Tocantins (-20p.p.), sendo acompanhado por outros 18 estados, como Amazonas (-19p.p.), Pará (-16p.p.), Alagoas (-13p.p.), Espírito Santo (-12p.p.), Distrito Federal (-12p.p.), Pará (-12p.p.), Sergipe (-11p.p.) e Rio Grande do Sul (10p.p.).

$\mathrm{Na}$ indústria de baixa tecnologia os maiores decréscimos no VTI/VBPI foram para Acre (-20p.p.), Pará (-14p.p.), Tocantins (-10p.p.), Amapá (-8p.p.), Rondônia (-8p.p.), Rio de J aneiro (-5p.p.), Minas Gerais (-4p.p.), São Paulo (-4 p.p.), Paraná (-3p.p.), Sergipe (-3p.p.), Pernambuco (-2p.p.), Bahia (-0,7p.p.) e Rio Grande do Sul (-0,5p.p.). Roraima não sofreu redução da relação VTI/VBPI em nenhum grupo de intensidade tecnológica, implicando em uma ausência de desindustrialização. Ressalta-se que este estado não possui indústria de alta e média-alta tecnologia.

Alguns estados apresentaram estabilidade na relação VTI/VBPI com uma tendência de fortalecimento, como Distrito Federal (para indústria de alta, média-alta, e baixa intensidade tecnológica e Paraíba (redução do VTI/VBPI apenas para a indústria de alta tecnologia). Nestes estados, este indicador não aponta para um processo de desindustrialização.

Portanto, o indicador de densidade produtiva vai ao encontro dos resultados apresentados nas seções anteriores, corroborando a existência de um processo de desindustrialização relativa, especialmente no período de 1996 a 2006, quando se observa uma redução nos valores de VTI/VBPI no total da indústria e nos diferentes grupos industriais, segundo a intensidade tecnológica. Porém, a partir de 2007 verifica-se uma nova direção desse indicador, com uma contenção da trajetória de queda que havia sendo verificada. Nos últimos três anos analisados alguns estados mostraram uma tendência de recuperação e aumento na relação VTI/ VBPI, o que ocorreu em Roraima, Espírito Santo, Pará, Mato Grosso do Sul, Paraíba, Rio de Janeiro, Goiás, Rio Grande do Norte, Minas Gerais e Bahia 1. A estabilidade do indicador foi verificada para o Maranhão, Sergipe, Ceará e Amazonas se mantiveram estáveis, com tendência de aumento em alguns deles. Em contraposição, Acre não apresentou nenhuma recuperação, juntamente com o Amapá, que tiveram uma tendência à queda no indicador de densidade produtiva nos últimos anos analisados.

Conforme ressaltado anteriormente, o indicador de densidade produtiva não aponta para nenhuma tendência regional específica. A queda ao longo do período e o aumento nos últimos anos não aponta tendência de perda de importância das regiões com grau mais elevado de industrialização e ganhos nas 
demais e, tampouco, de mudanças nas especializações regionais da indústria, analisada segundo a intensidade tecnológica de suas atividades. O que a análise deste indicador reforça é a ocorrência de um processo de perda de importância da produção local em diversas cadeias produtivas, o que poderá ser também aferido com os dados de inserção externa, apresentados na próxima subseção.

\subsection{Evolução da Inserção Externa Industrial}

A última fonte de informação utilizada no trabalho para verificar como o processo de desindustrialização em curso na economia brasileira se desdobra no nível estadual diz respeito à análise da inserção externa industrial.

Ao longo do período 1990-2013 houve, na maioria dos estados brasileiros, um aumento expressivo do valor das exportações e importações industriais. A tendência que se apresentou nos últimos anos foi a de um significativo e crescente déficit na balança comercial da indústria e da indústria de transformação (gráfico6).

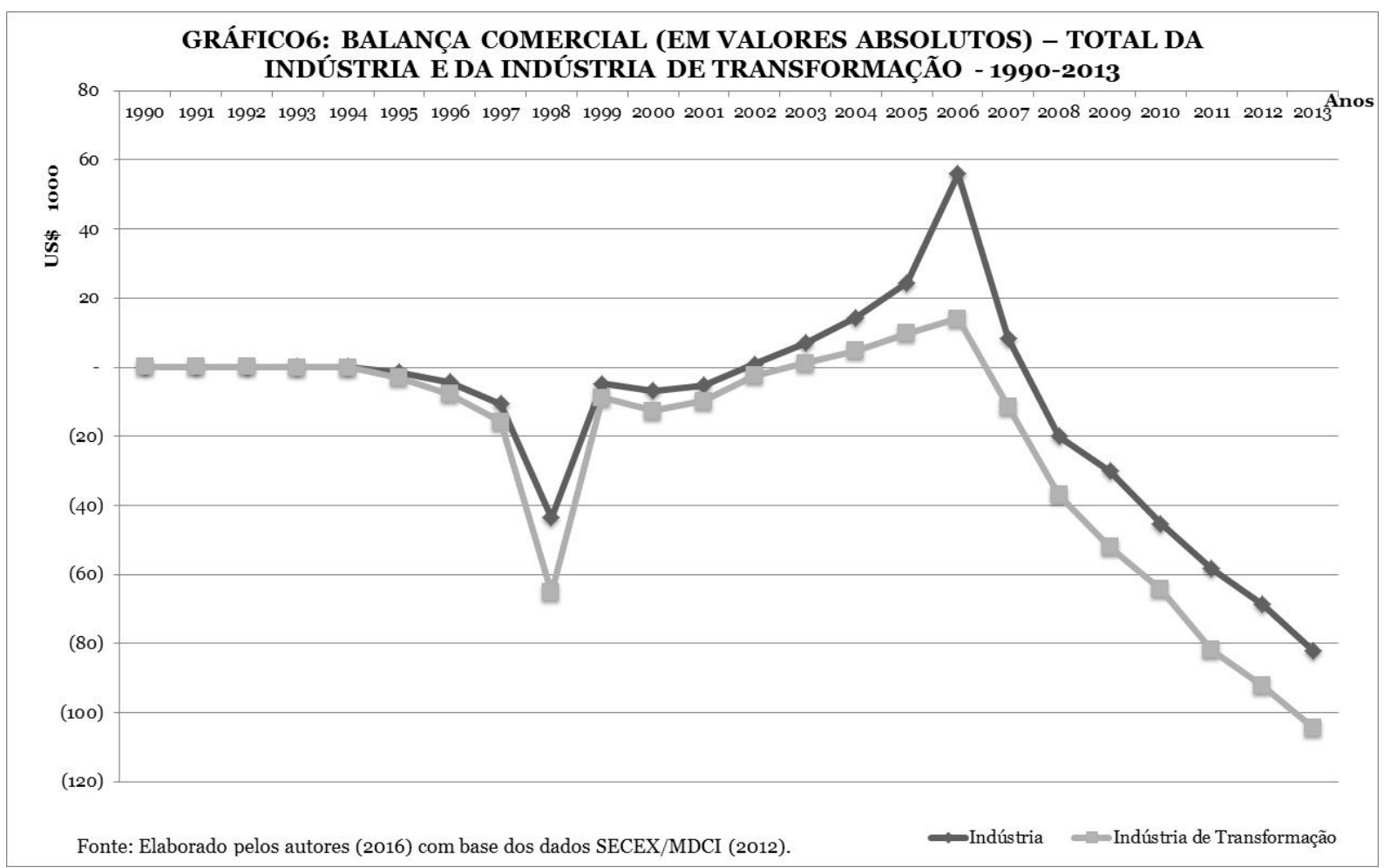

Já em termos relativos, os produtos industriais tiveram uma grande redução de participação nas exportações do Brasil, com uma perda de 34p.p. ao longo do período analisado. Os dados dispostos no gráfico7 mostram que apenas dois estados brasileiros não acompanharam essa trajetória de queda das exportações industriais, Santa Catarina e Ceará. Alguns estados vinham apresentando uma tendência de recuperação nos valores relativos, como o Piauí a partir de 2008, e Pernambuco a partir de 2007, mas não conseguiram manter essa recuperação a partir de 2011. 
As maiores reduções de participação da indústria nas exportações de cada estado foram verificadas nos estados de Rondônia (-77p.p), Pará (-76p.p, Tocantins (-59p.p.), Espírito Santo (-56p.p.) e Rio deJ aneiro (-54).

Considerando-se a classificação por intensidade tecnológica, a indústria de baixa tecnologia apresentou os maiores valores de participação nas exportações brasileiras, porém observa-se que houve uma queda nessa participação -3,1 p.p de 1990 a 2013. As maiores perdas foram na indústria de média-baixa tecnologia que reduziu a sua participação nas exportações brasileiras de $26,4 \%$ (1990) para 13,6\% (2013) e na indústria de alta tecnologia de 12,6\% (1990) para $0,3 \%$ (2013). O destaque foi para a indústria de média-alta tecnologia que apresentou ganhos de participação nas exportações, em torno de 1,22p.p. de 1990 a 2013.

Os estados que apresentaram diminuições do grupo de indústria de alta tecnologia nas exportações foram Rio de J aneiro, Minas Gerais, São Paulo, Rio Grande do Sul, Bahia, Pernambuco, Goiás, Ceará e Distrito Federal, embora a queda tenha sido inferior a 1p.p., com exceção de Rio de Janeiro com uma redução de -2,9p.p., Minas Gerais com -1,7p.p. e São Paulo, que teve um decréscimo de -1,2p.p. Ademais, Minas Gerais também apresentou redução da participação da indústria de média-alta tecnologia nas exportações, com uma redução de -9,7p.p. Neste caso, outros seis estados também apresentaram uma diminuição do grupo de média-alta tecnologia na pauta exportadora, destacando Piauí (-28p.p.) e Maranhão (-11p.p.).

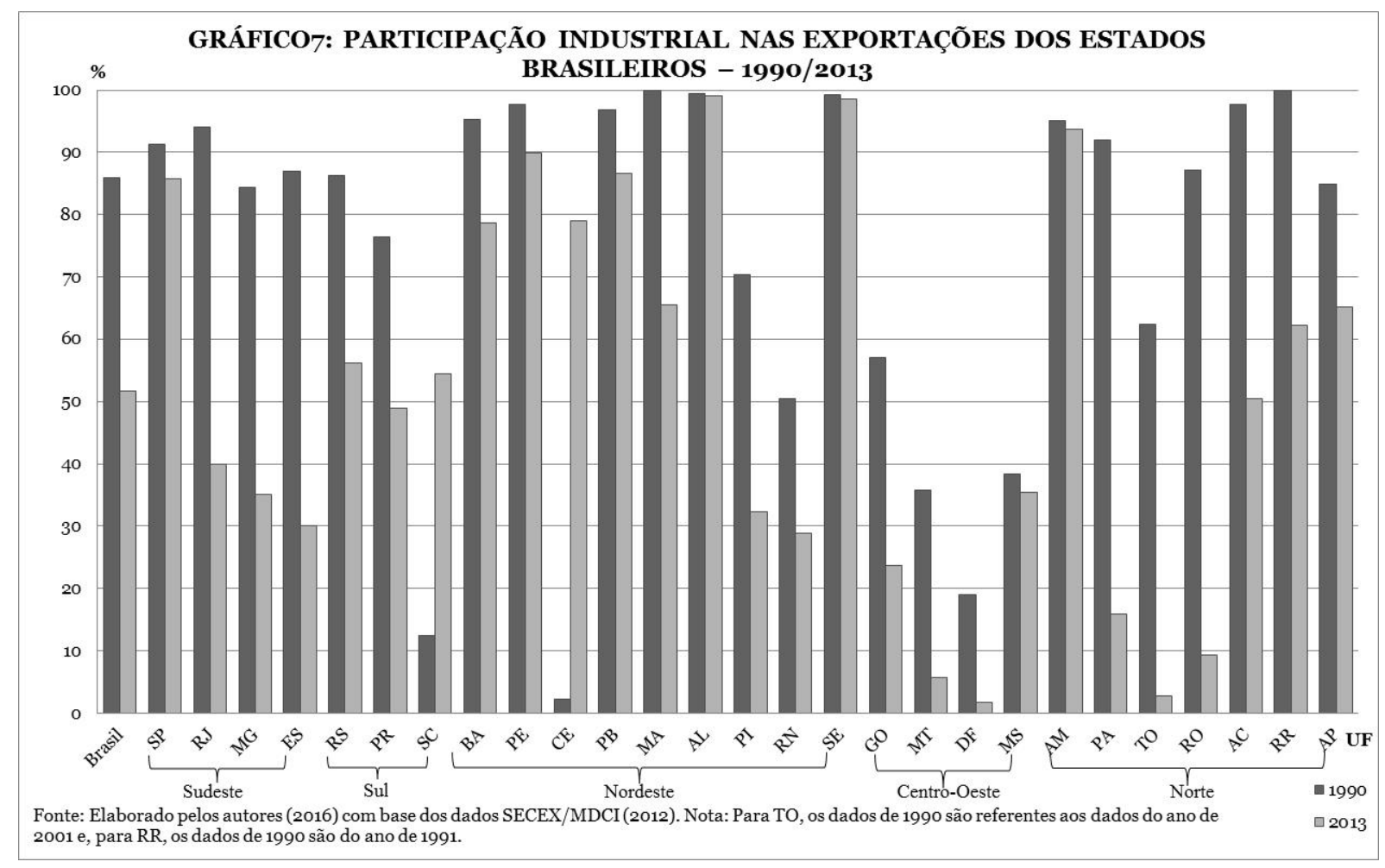


Com relação à evolução das importações, verifica-se, no período em consideração, que 14 estados apresentaram uma redução da participação da indústria nas importações, caracterizando uma menor dependência industrial das economias externas, destaque para Mato Grosso do Sul (-69,3p.p.), Rio Grande do Norte (-21,8p.p.), Sergipe (-18p.p.), Rio de J aneiro (-15,6p.p.). Em contraposição, as indústrias de Goiás e Rondônia foram as que ficaram mais dependentes das importações (gráfico7).

$\mathrm{Na}$ indústria de alta tecnologia, os principais estados que ficaram menos dependentes das importações foram Piauí, com uma redução de 37p.p., e Minas Gerais, que teve um decréscimo de 16 pontos percentuais. Em contraposição, Amazonas e Goiás se tornaram mais dependentes das importações na indústria de alta tecnologia, apresentando um aumento de participação de 37p.p. e 12p.p., respectivamente. Já a participação da indústria de média-alta tecnologia nas importações diminui em oito estados, sendo que a maior redução, de -45p.p., ocorreu em Mato Grosso do Sul. Em 18 estados (incluindo o Distrito Federal), a indústria de média-baixa tecnologia apresentou uma redução na pauta importadora, sendo que em sete estados a redução foi superior a 20 p.p. (Acre, Sergipe, Espírito Santo, Tocantins, São Paulo, Santa Catarina e Rondônia).

Dessa maneira, ao analisar os valores das exportações e importações do Brasil, observa-se que as importações são dominadas por produtos de média e alta tecnologia, enquanto as exportações são majoritariamente dominadas por commodities primárias.

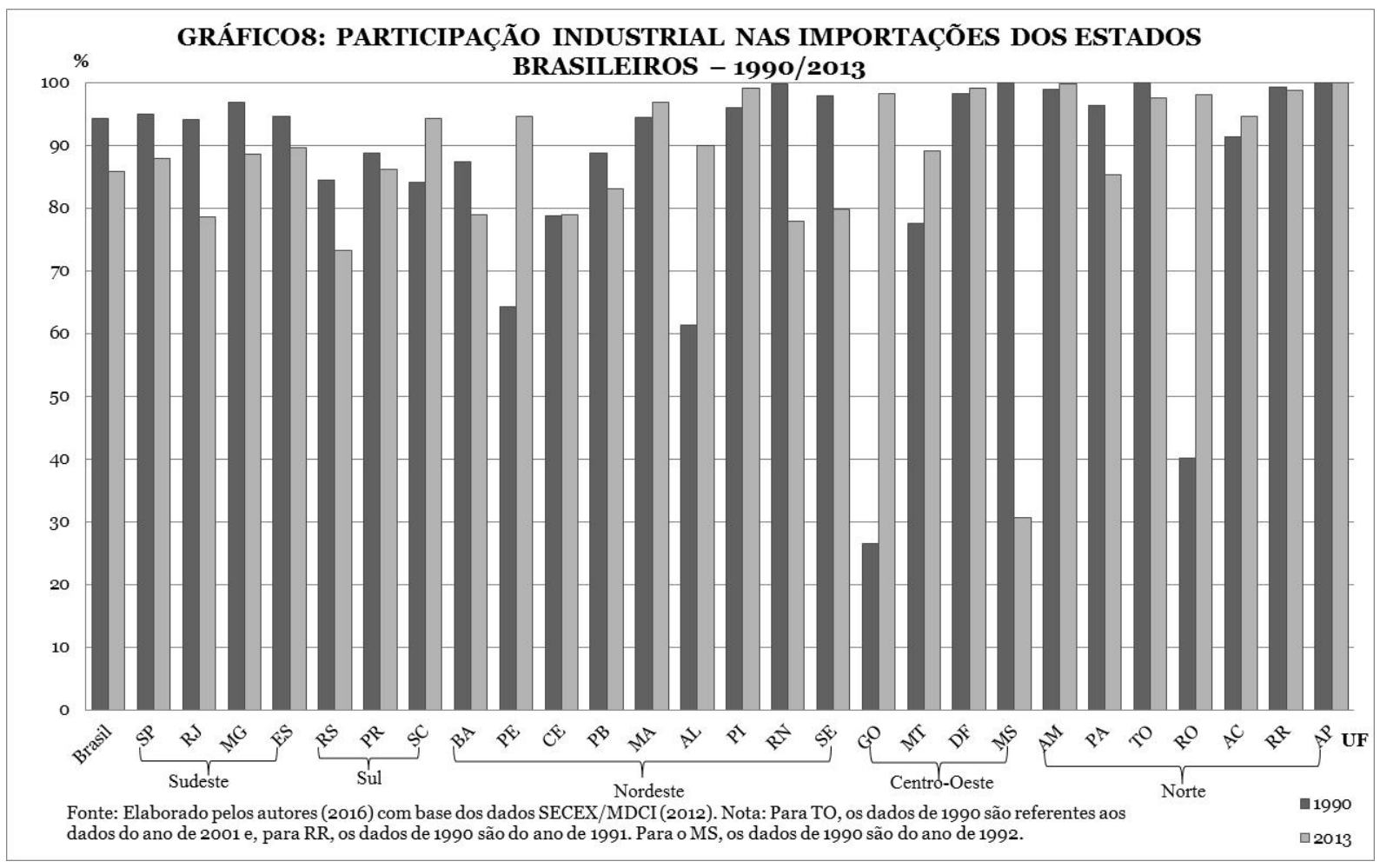


Os quadros 1 e 2 sintetizam os resultados encontrados pela pesquisa. Tomando como referência os conceitos de desindustrialização absoluta e relativa, verificase que para a maior parte dos estados brasileiros há fortes evidências de um processo de desindustrialização relativa. O fato de os principais indicadores positivos, de não ocorrência de desindustrialização relativa, situarem-se nos estados do Centro-Oeste e do Norte do país deve ser analisado com cautela, em função de serem regiões cuja base industrial é muito pequena. Nestes dois casos, os resultados positivos parecem estar relacionados mais intensamente à agroindústria, decorrente da expansão da fronteira agrícola nestas regiões.

As evidências de um processo de desindustrialização mais intenso nas regiões Sul e Sudeste devem ser relativizadas pelos dados que indicam que, tomando-se como referência a classificação setorial segundo a intensidade tecnológica, os estados destas regiões não perderam participação relativa de forma significativa, o que vai ao encontro dos resultados encontrados por Cruz e Santos (2011).

É importante destacar que, quando se analisam as séries históricas dos dados que compuseram este trabalho, há nos anos de 2006 a 2010 um processo de retomada da produção industrial, apesar da queda acentuada em 2009. Sarti e Hiratuka (2010) veem nesta retomada sinais de vigor da indústria, desautorizando a tese de um processo de desindustrialização irreversível na economia brasileira. Entretanto, este processo de retomada foi interrompido pela crise internacional deflagrada em 2008 e agravada nos anos subsequentes. No período 2011-13, os dados indicam a continuidade da trajetória anterior ao período da retomada, ou seja, de queda da produção industrial, em termos absolutos e relativos, e continuidade do processo de desindustrialização.

\begin{tabular}{|c|c|c|c|c|c|c|}
\hline \multicolumn{7}{|c|}{ QUADRO 1: SÍNTESE DOS INDICADORES (VALORES RELATIVOS) } \\
\hline Estado & PIB industrial & Emprego & Produtividade & Densidade & Exportação & Importação \\
\hline Brasil & - & - & + & - & - & - \\
\hline $\mathrm{SP}$ & - & - & + & - & - & - \\
\hline $\mathrm{RJ}$ & - & - & + & + & - & - \\
\hline MG & - & - & + & + & - & - \\
\hline $\mathrm{ES}$ & + & - & + & + & - & - \\
\hline $\mathrm{RS}$ & - & - & + & - & - & - \\
\hline PR & - & - & + & - & - & - \\
\hline SC & - & - & + & - & + & + \\
\hline $\mathrm{BA}$ & - & - & + & + & - & - \\
\hline $\mathrm{PE}$ & - & - & + & - & - & + \\
\hline $\mathrm{CE}$ & - & - & + & 1 & + & 1 \\
\hline $\mathrm{PB}$ & - & - & + & + & - & - \\
\hline MA & - & - & + & 1 & - & + \\
\hline $\mathrm{AL}$ & - & - & + & - & I & + \\
\hline PI & - & - & + & - & - & + \\
\hline $\mathrm{RN}$ & - & - & + & + & - & - \\
\hline
\end{tabular}




\begin{tabular}{|c|c|c|c|c|c|c|}
\hline SE & - & - & + & I & I & - \\
\hline GO & I & - & + & + & - & + \\
\hline $\mathrm{MT}$ & - & - & + & - & - & + \\
\hline $\mathrm{DF}$ & I & - & + & - & - & I \\
\hline MS & I & I & + & + & - & - \\
\hline $\mathrm{AM}$ & - & - & + & I & - & I \\
\hline PA & + & - & + & + & - & - \\
\hline TO & - & - & + & - & - & - \\
\hline RO & I & - & + & - & - & + \\
\hline $\mathrm{AC}$ & - & - & + & - & - & + \\
\hline $\mathrm{RR}$ & I & - & + & + & - & I \\
\hline $\mathrm{AP}$ & + & - & + & - & - & I \\
\hline
\end{tabular}

Fonte: Elaborado pelos autores (2016).

Nota: Neste e no quadro seguinte o sinal + significa que não houve desindustrialização relativa; o símbolo / significa que o indicador permaneceu estável; o sinal - significa que houve desindustrialização relativa. A partir do valor da variação percentual de cada indicador entre 1990 e 2010, adotou-se como critério de classificação: variação positiva acima de $1 \%$ foi atribuída o símbolo de mais (+), representando uma inexistência à tendência de desindustrialização relativa; variação entre -1\% e 1\%, foi considerada estável, sendo simbolizada pela barra (/ ); variação negativa, com uma redução superior a 1\%, significa tendência a desindustrialização relativa, representada pelo sinal de menos (-).

\begin{tabular}{|l|c|c|c|c|c|c|}
\hline \multicolumn{7}{|c|}{ QUADRO 2: SÍNTESE DOS INDICADORES (VALORES ABSOLUTOS) } \\
\hline Estado & PIB industrial & Emprego & VBPI & VTI & Exportação & Importação \\
\hline Brasil & + & + & + & + & + & + \\
\hline SP & + & - & + & + & + & + \\
\hline RJ & + & - & + & + & + & + \\
\hline MG & + & + & + & + & - & + \\
\hline ES & + & + & + & + & - & + \\
\hline RS & + & + & + & + & + & + \\
\hline PR & + & + & + & + & + & + \\
\hline SC & + & + & + & + & - & + \\
\hline BA & - & + & + & + & + & + \\
\hline PE & + & - & + & + & + & + \\
\hline CE & + & + & + & + & + & + \\
\hline PB & + & + & + & + & - & + \\
\hline MA & + & + & + & + & + & + \\
\hline AL & + & + & + & + & - & + \\
\hline PI & + & + & + & + & - & + \\
\hline RN & + & + & + & + & - & + \\
\hline SE & + & + & + & + & + \\
\hline GO & + & + & + & + \\
\hline
\end{tabular}




\begin{tabular}{|l|c|c|c|c|c|c|} 
MT & + & + & + & + & + & + \\
\hline $\mathrm{DF}$ & + & + & + & + & + & + \\
\hline $\mathrm{MS}$ & + & + & + & + & + & + \\
\hline $\mathrm{AM}$ & + & + & + & + & + & + \\
\hline $\mathrm{PA}$ & + & + & + & + & - & + \\
\hline $\mathrm{TO}$ & + & + & + & + & + & + \\
\hline $\mathrm{RO}$ & + & + & + & + & + & + \\
\hline $\mathrm{AC}$ & + & + & + & + & - & + \\
\hline $\mathrm{RR}$ & + & + & + & + & + & + \\
\hline AP & + & - & + & + & + & + \\
\hline Fonte: Elaborado pelos autores (2016).
\end{tabular}

Considerações Finais

Os dados analisados neste trabalho corroboram a tese de um processo de desindustrialização em curso na economia brasileira. Embora os dados absolutos indiquem ganhos no período em análise, os dados relativos sugerem perda de importância da indústria como motor da economia.

A partir deste pressuposto, analisou-se como este processo se apresentou nos estados e regiões brasileiros, a fim de verificar se apresentava sinais de um processo mais intenso nas regiões mais industrializadas e, com isso, se o processo teria como subproduto (desejável, por suposto), menores desigualdades regionais na distribuição da produção industrial no território brasileiro.

A partir de indicadores de valor adicionado, emprego, produtividade, densidade industrial e inserção externa pode-se concluir que a incidência do processo de desindustrialização nos estados e grandes regiões brasileiras não foi suficiente para alterar, de forma significativa, a forte concentração da indústria no SulSudeste do país. Embora alguns estados das regiões menos industrializadas tenham galgado importantes posições no período em análise, estes ganhos não alteraram, de forma significativa, a histórica desigualdade regional brasileira no tocante à localização industrial. Em especial, as indústrias classificadas como de média-alta e alta tecnologia permanecem concentradas na área do polígono industrial, conforme a definição de Diniz (1993), não tendo sido verificadas para estas indústrias processos importantes de relocalização no período em análise.

Outro aspecto importante identificado pelos indicadores trabalhados neste artigo é que, quando da recuperação do crescimento econômico na segunda metade dos anos 2000 e da crise após 2010, as reações dos estados em termos de crescimento industrial são divergentes, não sendo possível estabelecer tendência de industrialização ou desindustrialização. Este aspecto deve ser analisado em trabalhos futuros com dados mais recentes, que permitam avaliar os elementos de natureza estrutural, tanto no breve período de recuperação como no de crise, que se aprofundou nos últimos anos. 


\section{Referências}

ALMEIDA, J.S.G.; FEIJÓ, C.A.; CARVALHO, P.G.M. (2007). Mudança estrutural e produtividade industrial. São Paulo: IEDI.

BONELLI, R. (2008). Industrialização e Desenvolvimento: notas e conjecturas com foco na experiência do Brasil. Conferência de Industrialização, Desindustrialização e Desenvolvimento, Federação das Indústrias do Estado de São Paulo.

BONELLI, R.; PESSOA, S. (2010) Desindustrialização no Brasil: um resumo da evidência, Centro de Desenvolvimento Econômico, Ibre-FGV, Texto para Discussão 7.

BONELLI, R.; PESSOA, S.; MATOS, S. (2013). Desindustrialização no Brasil: Fatos e Interpretação". In: BACHA, E.; DE BOLLE, M.B (orgs.). O Futuro da Indústria no Brasil, Editora Civilização Brasileira, Rio de J aneiro.

Bresser-Pereira, L.C; Nassif, A; Feijó, C. (2016). "A Reconstrução da Indústria Nacional: a conexão entre o regime macroeconômico e a política industrial". Revista de Economia Política, 36(3):493-513.

CARDOZO, S.A. (2010). Guerra Fiscal no Brasil e alterações das estruturas produtivas estaduais desde os anos 1990. 2010. 340p. Tese (Doutorado em Desenvolvimento Econômico) - IE/ UNICAMP. Campinas.

CARVALHO, P. G. M.; FEIJ O' , C. A. (2000). Produtividade industrial no Brasil: o debate recente. Indicadores Econo micos FEE: ana' lise conjuntural, Porto Alegre, v.28 (3), setembro.

CRUZ, B.O.; SANTOS, I.R.S. (2011). Dinâmica do Emprego Industrial no Brasil entre 1990 e 2009: Uma Visão Regional da Desindustrialização. Disponível em: <http:// www.ipea.gov.br/portal/images/stories/PDFs/TDs/td_1673.pdf>. Acesso em:out.2013.

DINIZ, C.C. (1993). "Desenvolvimento poligonal no Brasil: nem desconcentração, nem contínua polarização". Revista Nova Economia 3 (1): 3564.

FEIJ O', C. A.; CARVALHO, P. G. M. (1993). Produção, emprego, salá rio e produtividade industrial em 1992: um ano de paradoxos. Indicadores Econo micos FEE: ana lise conjuntural, Porto Alegre, v.21(1), maio.

FEDERAÇÃO DAS INDÚSTRIA DO ESTADO DE SÃO PAULO (FIESP) (2015). A Participação da Indústria de Transformação no PIB: Novas Séries, Piores Resultados. DECOMTEC, São Paulo, maio.

HIRSCHMAN, A.O. (1958). The strategy of economic development. New Haven: Yale University Press.

INSTITUTO BRASILEIRO DE GEOGRAFIA E ESTATÍSTICA (IBGE). (2013a). Contas Regionais do Brasil. 2013. Disponível em: 〈http://www.ibge.gov.br>. Acesso em:nov.2012. 
INSTITUTO BRASILEIRO DE GEOGRAFIA E ESTATÍSTICA (IBGE). (2013b). Pesquisa Industrial Anual. Disponível em:<http://www.ibge.gov.br>. Acesso em nov.2012.

KALDOR, N. (1957). "A Model of Economic Growth". The Economic J ournal 67 (268): 591-624.

KALDOR, N. (1989). The case for regional policies. In TARGETTI, F.; THIRWWALL,A. The essential Kaldor. NewYork: Holmes \& Meier.

KUPFER, D. (2012). Industrialização e Desenvolvimento: Desafios e Tendências. Disponível em: 〈http://www.slideshare.net/ Desenbahia/2012-0920-kupfer-eeb-v1>. Acesso em:jan.2013.

LEMOS, M.B.; DINIZ, C.C.; GUERRA, L.P.. (2003). "A Nova Configuração Regional Brasileira e sua Geografia Econômica". Estudos Econômicos 33(4): p.665-700.

NASSIF, A. (2008). "Há Evidências de Desindustrialização no Brasil?" Revista de Economia Política 28 (1): 72-96.

Nassif, A.; Feijó, C.; Araújo, E. (2015). "Structural change and economic development: is Brazil catching up or falling behind?" Cambridge J ournal of Economics, 39:1307- 1332.

ORGANIZATION FOR ECONOMIC COOPERATION AND DEVELOPMENT (OECD). (2005). Directorate for Science, Technology and Industry, STAN Indicators.

Disponível

em: <http:// www.oecd.org/ industry/ industryandglobalisation/40230754.pdf>.

Acesso em: nov.2012.

OREIRO, J.L. (2009). Desindustrialização: conceituação, causas, efeitos e o caso brasileiro. Disponível em: বhttps://jlcoreiro.wordpress.com/2009/12/22/desindustrializacaoconceituacao-causas-efeitos-e-o-caso-brasileiro >. Acesso em:nov.2012.

OREIRO, J.L.; FEIJ Ó, C.A. "Desindustrialização: conceituação, causas, efeitos e o caso brasileiro". Revista de Economia Política, São Paulo 30 (2):219-232.

PALMA, G. (2005). Four sources of deindustrialization and a new concept of Dutch disease. In: O campo, J. (org.) Beyond reforms: structural dynamics and macroeconomic vulnerability. Stanford University Press and World Bank.

RELAÇÃO ANUAL DE INFORMAÇÕES SOCIAIS (RAIS). (2012). Disponível em: <http:// www.mte.gov.br/ geral/ estatisticas.asp?viewarea=caged>. Acesso em:nov.2012.

ROWTHORN, R; RAMASWANY, R. (1999). Growth, Trade and Deindustrialization. IMF Staff Papers 46 (1).

SAMPAIO, D.P. A desindustrialização em marcha no Brasil: uma análise comparada. Anais de XVII Encontro Nacional de Economia Política, Rio de Janeiro/RJ , jun.2012.

SARTI, F.; HIRATUKA, C. (2010). Indústria mundial: mudanças e tendências recentes. Texto para Discussão, n.186, Campinas: Unicamp. IE. 
SECRETARIA DO COMÉRCIO EXTERIOR DO MINISTÉRIO DO DESENVOLVIMENTO, INDÚSTRIA E COMÉRCIO EXTERIOR (SECEX/MDIC). (2013)B. Disponível em: $<$ http:/ / www.mdic.gov.br/ / sitio/ interna/interna.php?area $=5 \& m e n u=1078$ \&ref $\mathrm{r}=1076>$. Acesso em: nov.2012

SILVA, H.C.; CARIO, S.A.F. (21012). O processo de desindustrialização: uma avaliação sob a perspectiva da economia brasileira (1990-2010). Anais do XV Encontro de Economia da Região Sul/ Anpec Sul, Porto Alegre/ RS.

SOARES, C; TEIXEIRA, A; OREIRO, J.L (2011). Uma análise empírica dos determinantes da desindustrialização no caso brasileiro (1996-2008). Disponível em: <http://www.sep.org.br/artigos/download?id=1814>. Acesso em: 27 out. 2016.

SQUEFF, G. C. (2009). Desindustrialização em Debate: aspectos teóricos e alguns fatos estilizados da economia brasileira. In: Radar: tecnologia, produção e comércio exterior. Instituto de Pesquisa Econômica Aplicada. Diretoria de Estudos e Políticas Setoriais, de Inovação, Regulação e Infraestrutura. Brasília. n.1.

TREGENNA, F. (2009). "Characterizing deindustrialization: an analysis of changes in manufacturing employment and output internationally". Cambridge J ournal of Economics 33: 433-466.

VERÍSSIMO, M.P. (2010). Doença Holandesa no Brasil: Ensaios sobre Taxa de Câmbio, Perfil Exportador, Desindustrialização e Crescimento Econômico. 2010. Tese (Doutorado em Economia) - IE/ UFU. Uberlândia/ MG. 


\section{Anexo 1}

\begin{tabular}{|c|c|c|c|c|c|c|c|c|c|c|c|c|}
\hline \multirow{3}{*}{ UF } & \multicolumn{12}{|c|}{ TABELA 1: PIB INDUST RIAL, EMPREGO, VBPI, VTI, FOB EXPORT AÇÃO E FOB I MPORTAÇÃO DA INDÚST RIA - EM TERMOS ABSOLUTOS } \\
\hline & \multicolumn{2}{|c|}{ PIB Industrial (em 1000 R $\$$ ) } & \multicolumn{2}{|c|}{ Emprego } & \multicolumn{2}{|c|}{ VBPI (em 1000 R\$) } & \multicolumn{2}{|c|}{\begin{tabular}{|l|} 
VTI (em 1000 R\$) \\
\end{tabular}} & \multicolumn{2}{|c|}{ Exportação (US\$) } & \multicolumn{2}{|c|}{ Importação (US\$) } \\
\hline & 1996 & 2013 & 1990 & 2013 & 1996 & 2012 & 1996 & 2012 & 1990 & 2013 & 1990 & 2013 \\
\hline Brasil & 506.429 & 745.913 & 6.877 .909 & 8.554 .122 & 362.212 .068 & 2.150 .737 .869 & 171.188 .466 & 976.116 .200 & 94.275 .047 & \begin{tabular}{|l|}
127.296 .241 \\
\end{tabular} & 64.854 .516 & 210.329 .098 \\
\hline SP & 212.997 & 223.004 & \begin{tabular}{|l|}
2.899 .702 \\
\end{tabular} & 2.843 .891 & \begin{tabular}{|l|}
175.312 .272 \\
\end{tabular} & 786.606 .561 & \begin{tabular}{|l|}
84.785 .537 \\
\end{tabular} & 341.555 .788 & 35.288 .960 & \begin{tabular}{|l|}
48.317 .942 \\
\end{tabular} & 29.433 .562 & 78.934 .797 \\
\hline $\mathrm{RJ}$ & 51.169 & 116.904 & 690.276 & 520.955 & 26.319 .861 & 184.315 .567 & 14.902 .090 & 109.835 .563 & 4.648 .895 & 8.486 .573 & 15.360 .643 & 16.940 .350 \\
\hline MG & 48.127 & 89.768 & 635.325 & 917.575 & 35.756 .647 & 237.700 .176 & \begin{tabular}{|l|}
15.604 .425 \\
\end{tabular} & 108.906 .545 & 14.716 .050 & 11.726 .003 & 2.525 .383 & 10.930 .840 \\
\hline ES & 8.069 & 31.715 & 94.324 & 139.237 & 4.929 .922 & 47.301 .450 & 2.252 .984 & 27.976 .098 & 4.181 .234 & 3.282 .139 & 1.913 .869 & 6.666 .600 \\
\hline $\mathrm{RS}$ & 49.746 & 50.681 & 578.439 & 753.684 & 28.662 .368 & 168.453 .233 & 12.740 .659 & 68.818 .802 & 10.090 .851 & 14.088 .228 & 3.560 .722 & 12.260 .496 \\
\hline PR & 26.506 & 47.431 & 359.241 & 717.059 & 20.419 .478 & 168.101.615 & \begin{tabular}{|l|}
8.818 .652 \\
\end{tabular} & 68.149 .618 & 4.846 .326 & 8.916 .488 & 1.886 .307 & 16.654 .565 \\
\hline $\mathrm{SC}$ & 27.749 & 40.477 & 356.487 & 688.877 & 16.372 .019 & 107.773 .949 & 7.544 .185 & 47.597 .457 & 4.748 .590 & 4.725 .837 & 932.489 & 13.936 .858 \\
\hline $\mathrm{BA}$ & 18.564 & 18.390 & 187.753 & 245.359 & 11.123 .052 & 91.567 .277 & 4.655 .841 & 39.556 .573 & 4.700 .835 & 7.943 .745 & 2.680 .488 & 7.021 .750 \\
\hline $\mathrm{PE}$ & 9.439 & 12.834 & 261.421 & 242.611 & 5.228 .471 & 35.392 .047 & 2.725 .151 & 16.928 .256 & 1.328 .247 & 1.791 .552 & 494.468 & 6.454 .304 \\
\hline $\mathrm{CE}$ & 6.143 & 10.442 & 125.053 & 267.402 & 4.017 .209 & 24.669 .390 & 1.975 .020 & 11.822 .958 & 253.871 & 7.021 .750 & 303.802 & 7.021 .750 \\
\hline $\mathrm{PB}$ & 2.341 & 3.580 & 58.496 & 82.481 & 1.355 .071 & 8.502 .514 & 621.581 & 4.201 .420 & 172.937 & 162.826 & 102.682 & 544.725 \\
\hline MA & 2.106 & 4.381 & 37.390 & 45.655 & 1.324 .558 & 11.000 .210 & 563.440 & 4.658 .693 & 1.502 .028 & 1.533 .996 & 325.697 & 6.611 .393 \\
\hline $\mathrm{AL}$ & 2.175 & 3.048 & 74.954 & 93.867 & 2.146 .253 & 7.238 .554 & 1.183 .999 & 3.879 .418 & 984.662 & 735.085 & 123.821 & 445.966 \\
\hline PI & 975 & 1.086 & 28.400 & 30.205 & 397.950 & 3.368 .215 & 189.594 & 1.405 .383 & 77.461 & 52.295 & 20.760 & 194.987 \\
\hline $\mathrm{RN}$ & 2.771 & 5.840 & 52.047 & 78.172 & 1.327 .305 & 11.109 .411 & 787.668 & 6.744 .706 & 152.162 & 71.779 & 74.105 & 206.989 \\
\hline SE & 2.687 & 4.589 & 42.097 & $\begin{array}{r}51.765 \\
\end{array}$ & 877.619 & 7.750 .303 & 403.512 & 3.544 .669 & 128.746 & 83.354 & 78.653 & 231.634 \\
\hline $\mathrm{GO}$ & 5.224 & 19.190 & 91.372 & 257.388 & 4.805 .754 & 61.562 .172 & 1.809 .021 & 25.426 .899 & 391.337 & 1.671 .238 & 84.861 & 4.755 .929 \\
\hline MT & 2.460 & 6.874 & 36.668 & 112.965 & 1.999 .638 & 36.025 .968 & 783.650 & 12.605 .154 & 309.069 & 912.176 & 59.310 & 1.520 .171 \\
\hline $\mathrm{DF}$ & 1.241 & 2.062 & 38.998 & \begin{tabular}{|l|}
40.997 \\
\end{tabular} & 678.839 & 4.571 .019 & 345.037 & 2.243 .245 & 1.866 & $\begin{array}{r}4.341 \\
\end{array}$ & 250.449 & 1.338 .980 \\
\hline MS & 2.456 & 6.959 & 32.423 & 98.597 & 1.997 .304 & 25.707 .700 & 616.653 & 9.959 .359 & 136.382 & 1.864 .181 & 1.112 & 1.734 .296 \\
\hline $\mathrm{AM}$ & 15.877 & 19.417 & 85.970 & 142.626 & 13.392 .296 & 68.595 .552 & 5.949 .461 & 30.049 .192 & 577.154 & 991.495 & 3.902 .910 & 14.084 .585 \\
\hline $\mathrm{PA}$ & 6.085 & 23.029 & 81.169 & 108.331 & 3.247 .614 & 41.629 .051 & 1.688 .039 & 26.111 .645 & 4.840 .139 & 2.514 .215 & 707.073 & 947590 \\
\hline TO & 262 & 866 & 2.846 & 18.146 & 96.558 & 2.980 .007 & 31.754 & 858.615 & 1.178 & 19.846 & 8.224 & 182.293 \\
\hline $\mathrm{RO}$ & 775 & 2.058 & 13.675 & 39.625 & 227.021 & 6.766 .535 & 90.488 & 2.178 .035 & 28.003 & 96.907 & $\begin{array}{r}9.414 \\
\end{array}$ & 602.628 \\
\hline $\mathrm{AC}$ & 263 & 383 & 5.071 & 7.222 & 18.784 & 652.278 & 11.097 & 269.552 & 8.852 & 5.735 & 95,59147011 & 1.899 \\
\hline $\mathrm{RR}$ & 29 & 144 & 2.125 & 3.359 & 6.724 & 116.973 & 2.047 & 71.480 & 617 & 4.986 & 4.526 & 6.783 \\
\hline AP & 193 & 763 & 6.187 & 6.071 & 171.477 & 1.280 .142 & 106.879 & 761.077 & 158.595 & 271.529 & 9.090 & 95.940 \\
\hline
\end{tabular}

Fonte: Elaborada pelas autoras (2016) com base dos dados IBGE (2013a; 2013b), RAIS (2013) e SECEX/ MDIC (2013). 